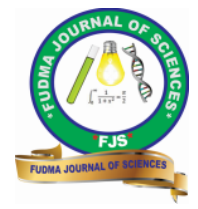

FUDMA Journal of Sciences (FJS)

ISSN online: $2616-1370$

ISSN print: 2645 - 2944

Vol. 4 No. 3, September, 2020, pp $464-469$

DOI: https://doi.org/10.33003/fjs-2020-0403-366

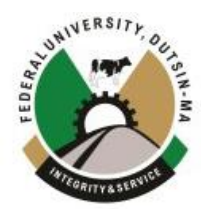

\title{
IN VITRO SCREENING OF COLIPHAGE EFFICACY AGAINST MULTIDRUG DRUG RESISTANT CLINICAL ISOLATES OF ESCHERICHIA COLI
}

\author{
*1'Sulaiman, M. A., ${ }^{1}$ Kawuni, J., ${ }^{1}$ Madika, A., ${ }^{1}$ Musa B., ${ }^{1}$ Tijjani, M. B., ${ }^{1}$ Atta, H. I. and ${ }^{2}$ Musa Hassan Muhammad \\ ${ }^{1}$ Department of Microbiology, Ahmadu Bello University, Zaria, Kaduna State \\ ${ }^{2}$ Department of Microbiology and Biotechnology, Federal University, Dutse, Jigawa Sate
}

Corresponding Author's email: masulaiman@abu.edu.ng +2348038937309

\begin{abstract}
The incidence of multi-drug resistance (MDR) in bacteria has become a major problem in this era of modern medicine, making it necessary to look for other options that can be used to treat the infections caused by the MDR bacteria. Scientifically, one of the therapies that is now looking promising, is application of phage therapy. This research work was designed to determine the efficacy of coliphages isolated from sewage, against MDR clinical isolates of E. coli. Ten (10) clinical isolates were subjected to both microbiological conventional and PCR techniques for confirmation, thereafter, the confirmed isolates were tested against some 8 commonly used antibiotics using disk diffusion method to identify the MDR among them. The MDR isolates were subjected to various dilutions $\left(1: 10-1: 10^{8}\right)$ of coliphage recovered from sewage, sampled from 5 different locations and isolated by using double agar overlay method. Out of the 10 isolates collected, $8(80 \%)$ were confirmed as E. coli, all (8/8: 100\%) of which were MDR. However, 6(75\%) out of the 8 MDR E. coli, were lysed by the coliphages-observed as cytopathic effect in form of clear zones (plaques) within the bacterial lawn and were recorded from all the dilutions (100\%) tested and from all the locations $(100 \%)$ sampled. Conclusively, infection by MDR E. coli may be life threatening, as it is highly prevalent $(100 \%$ in our study). However, the coliphages were found to be abundant in sewage and the application of their therapy may provide a good alternative treatment against the MDR.
\end{abstract}

Keywords: Bacteriophages, Coliphages, Multi-drug resistance, Cytopathic effect, Plaque, Lytic effect, Phage therapy.

\section{INTRODUCTION}

Although there has been a success in administering antibiotics to treat infectious diseases, the emergence of MDR bacteria is now becoming a setback to that success (Principi et al., 2019). Such MDR bacteria include Escherichia coli, known to have some significant pathogenic strains, been associated with urinary tract infections, diarrhoea, meningitis and bacteremia; thus, their resistance to multiple drugs is a serious health challenge (Delmas et al., 2015). This deemed it necessary to seek for alternative methods of therapy (Sarker et al., 2016). Bacteriophages, also called phages are simply referred to as host-specific viruses that target and infect bacteria for replication (Adhikari, 2013). These viruses are so ubiquitous in nature and exist in environments wherever their suitable bacterial hosts exist. Such environments include sewage, soil and natural water bodies (Premarathne et al., 2017). Generally, phage's lytic life cycle results to the lysis of the bacterial host cell (Balcazar, 2017; Dubey et al., 2015; Karthik et al., 2014). Phage therapy is the therapeutic application of phages to treat infections of bacterial etiology (Premarathne et al., 2017), likewise coliphage (a bacteriophage which infect $E$. coli) therapy means application of the coliphage in the treatment of E. coli infections (Sulaiman and Usman, 2020). The therapy may be considered a good alternative against $E$. coli infections, especially the ones caused by MDR strains (Sarker et al., 2016). There are nine strains of coliphages, namely; the T-even phages; T2, T4 and T6, and the T- odd phages; T1, T3, T5 and T7 (Shende et al., 2017; Adhikari, 2013). Generally, the therapy is more effective when two or more strains of the phages are used as cocktail (Sarker et $a l, 2016)$. The major advantage of phage therapy is that there is only minute possibility of conferring side effect (such as allergies and reactions to the bacterial endotoxins), they have high level of selectivity and minimal possibility of inducing selfresistance (Morozova et al., 2018; Lin et al., 2017). This work was aimed at in vitro screening of coliphage efficacy isolated from sewages against multidrug resistant clinical isolates of $E$. coli.

\section{MATERIALS AND METHODS}

Source of Isolates

Ten clinical isolates of $E$. coli from faecal samples of gastroenteritis patients from our previous studies (Sulaiman, et al., 2019) were obtained in nutrient broth and used in the study.

\section{Bacterial Isolates Confirmation}

The isolates were first sub-cultured by streaking aseptically on Eosine Methylene Blue (EMB) agar plates and incubated at $37^{\circ} \mathrm{C}$ for 24 hours. The colonies typical of $E$. coli were further characterized by Gram staining carried out aseptically and observed under oil immersion objective lens (Cheesebrough, 2009). The isolates were further subjected to other tests including Methyl Red (MR)-Voges-Proskauer (VP), using MRVP broth (Oxoid), which was inoculated with pure colony and incubated overnight at $37^{\circ} \mathrm{C}$; subsequently $1 \mathrm{~mL}$ of the inoculated broth was aseptically transferred in to a sterilized test tube (to have a tube each for MR and VP tests). For the MR test, 5 drops of methyl red was added and for the VP test 3 drops of $6 \%$ alpha napthol and 1 drop of $40 \%$ potassium hydroxide were added respectively, thereafter the change in colour (red ring developed for MR test and pink colour formed within 15min for VP test) was observed. Additionally, indole test was carried out, where a colony was inoculated into peptone water and incubated at $37^{\circ} \mathrm{C}$ 
for 24 hours, then $0.5 \mathrm{ml}$ of Kovac's reagent was added and the reaction inform of colour development was observed. Finally, they were also tested for their ability to utilize citrate by streaking a pure discreet colony from the cultures of the respective isolates, on to Simmon's citrate agar slants, and were incubated at $37^{\circ} \mathrm{C}$ for 24 hours before the colour change was observed (Cheesebrough, 2009). The isolates re-characterized as $E$. coli conventionally, were further confirmed by using molecular techniques.

\section{Molecular Characterization Techniques \\ DNA Extraction}

The DNA extraction was carried out using boiling method (Slulaiman and Usman, 2020). Fresh cultures of the bacteria, grown overnight in Eppendorf tubes containing $1 \mathrm{~mL}$ of LuriaBertani (LB) broth and then centrifuged (Bio-Rad centrifuge, USA) at $6000 \mathrm{xg}$ for $10 \mathrm{~min}$. The supernatants were decanted and the sediments were suspended in $0.5 \mathrm{~mL}$ of $1 \mathrm{X}$ phosphatebuffered saline (PBS) and centrifuged for another 10min at same $6000 \mathrm{xg}$. The supernatants were decanted and the sediments were re-suspended in $0.5 \mathrm{~mL}$ of sterilized distilled water. The tubes were vortexed and boiled in heating block at $100^{\circ} \mathrm{C}$ for $10 \mathrm{~min}$. The tubes were incubated in ice for $20 \mathrm{~min}$ before were recentrifuged at $6000 \mathrm{xg}$ for another $10 \mathrm{~min}$. Then $0.5 \mathrm{~mL}$ of the supernatants (DNA) were pipetted into sterilized Eppendorf tubes $(1.5 \mathrm{~mL})$ and stored at $-2^{\circ} \mathrm{C}$ until further analysis (Slulaiman and Usman, 2020).

\section{Conventional PCR and Electrophoresis \\ The pair of primer used (F- 5'CCAGGCAAAGAGTTTATGTTGA3'R \\ 5'GCTATTTCCTGCCGATAAGAGA3') (Lindsay et al., 2017), were synthesized at Inqaba BioTec Inc (South Africa). Each reaction was prepared as $25 \mu 1$, containing $0.5 \mu \mathrm{L}(10 \mu \mathrm{mol})$ each of the forward and reverse primer, $12.5 \mu \mathrm{L}$ of the green master mix (Biolabs, England), $3 \mu \mathrm{L}$ of the DNA, and $8.5 \mu \mathrm{L}$ molecular grade water (Biolabs, England). The PCR condition was ran using a thermo cycler (BioRad, USA): initial denaturation at $94^{\circ} \mathrm{C}$ for $30 \mathrm{sec}$, then subsequent denaturation at $94^{\circ} \mathrm{C}$ for $30 \mathrm{sec}$, annealing at $48^{\circ} \mathrm{C}$ for $30 \mathrm{sec}$ and extension at $68^{\circ} \mathrm{C}$ for $60 \mathrm{sec}$, which were run for 35 cycles before the final extension at $68^{\circ} \mathrm{C}$ for $5 \mathrm{~min}$. The gene bands (212bp) were viewed and documented using UV light imaging system (BioDoc-It ${ }^{\mathrm{TM}}$ ).}

\section{Screening the Isolates for MDR}

The isolates confirmed (coded as EC1-EC8) (Table 2) were screened for antibiotic susceptibility using disk diffusion method (CLSI, 2018). Fresh cultures of the isolates were suspended in $0.5 \mathrm{ml}$ of sterilized $1 \mathrm{X}$ physiological saline and the turbidity was adjusted to $0.5 \mathrm{McF}$ arland standard scale. A $0.1 \mathrm{ml}$ from each of the standardized suspensions was streaked aseptically on to Mueller-Hinton agar plates and allowed for complete absorption before were seeded with the following antibiotics (Oxoid): sparfloxacin $(10 \mu \mathrm{g})$, ciprofloxacin $(30 \mu \mathrm{g})$, amoxacillin $(30 \mu \mathrm{g})$, augmentin $(10 \mu \mathrm{g})$, gentamycin $(30 \mu \mathrm{g})$, pefloxacin $(30 \mu \mathrm{g})$, ofloxacin $(10 \mu \mathrm{g})$, and streptomycin $(30 \mu \mathrm{g})$. The plates were incubated overnight at $37^{\circ} \mathrm{C}$ before were examined for zone of inhibitions, which were recorded and interpreted using CLSI manual (CLSI, 2018). The isolates that were resistant to at least 2 antibiotics of different classes (MDR) were further tested against the coliphage.
Sample (sewage) Collection for Isolation of Coliphages

The samples were collected from 5 different locations (coded as AL1-AL5) within ABU Zaria, using sterile containers (100mL). The containers were aseptically opened and lowered into the sewage collecting compartments. The bottles were removed when filled to the $50 \mathrm{~mL}$ and transported immediately (under room temperature protected from sun and UV light) to the laboratory, Department of Microbiology, ABU Zaria for analysis.

\section{Preparation of phage suspension}

Phage suspensions were prepared by transferring $10 \mathrm{~mL}$ of the samples each into a sterile test tube and centrifuged at 2000xg for $5 \mathrm{~min}$. After centrifugation, the supernatants were carefully and aseptically transferred each into a sterilized conical flask and aseptically filtered through a $0.22 \mu \mathrm{m}$ pore sized membrane filter (MF-Millipore) ${ }^{\mathrm{TM}}$ to remove particulates and bacterial cells (Beaudoin et al., 2007).

\section{Preparation of the Phage Dilutions}

The stock was prepared by mixing $20 \mu \mathrm{L}$ of the phage suspension with $180 \mu \mathrm{L}$ peptone water in a microtitre plate well (1:10). Furthermore, 7 more wells were dispensed each with $180 \mu \mathrm{L}$ of peptone water and from the stock $20 \mu \mathrm{L}$ was used to carry out serial dilution from $10^{-2}-10^{-8}$.

Determination of the Cytopathic Effects of the Coliphage Dilutions on MDR $E$. coli

Plaque Assay was used to determine the cytopathic effect of the coliphages against the clinical isolates of $E$. coli (Cappuccino and Sherman, 2014). A $10 \mu \mathrm{L}$ from 24 hours broth cultures of the MDR isolates each, was aseptically pipetted into the $5 \mathrm{~mL}$ of the soft agar (prepared as $0.9 \%$ in distilled water, kept in water bath maintained at $50^{\circ} \mathrm{C}$ ). The mixtures were shaken gently and each was overlaid aseptically onto a nutrient agar plate. The overlaid soft agar was allowed to solidify, and marker was used to divide each of the plates in to 8 parts. Then, $10 \mu \mathrm{L}$ from each of the eight different dilutions $\left(1: 10-1: 10^{8}\right)$ of the phage suspensions was inoculated on a different part on the plates. The plates were incubated aerobically at $37^{\circ} \mathrm{C}$ for 24 hours and examined for cytopathic effects.

\section{RESULTS}

Out of the 10 isolates collected, $8(80 \%)$ were confirmed as $E$. coli, being non-mucoid, blue-black colony with green metallic sheen on EMB agar. Also, they were Gram negative rods, Indole and MR positive, but VP and citrate negative. Furthermore, all the 8 isolates confirmed as $E$. coli by microbiological conventional techniques, were found to carry $E C$ gene (Plate I), which is unique for $E$. coli).

Absolute resistance (100\%) of the isolates was observed against augmentin and amoxicillin, which is followed by $75 \%$ resistance against sparfloxacin, pefloxacin and ofloxacin. Furthermore, a very high level of resistance of the isolates was recorded against streptomycin $(62.5 \%)$ and ciprofloxacin $(50 \%)$, with good level of efficacy $(62.5 \%)$ only observed in the activity of gentamicin (Table 1).

Furthermore, the evidence of the antibiotic resistance of the individual isolates was more pronounced, as all of them (100\%) showed significant MAR index $(\geq 0.2)$. The MAR index was highly significant, ranging from 0.625 (in isolates that resisted 5 out of the 8 antibiotics tested) to 1 (in isolates resistant to all the antibiotics tested) (Table 2). 
Coliphages were abundantly found to occur in all the 5 sewage locations (100\%) sampled (Table 3). Out of the 8 MDR E. coli tested, only $6(75 \%)$ were recognized, hosted and subsequently lysed by the coliphage (Table 3 ). however, even the lowest dilution of the phage suspension $\left(1: 10^{8}\right)$ was found to have enough coliphage to lyse the MDR E. coli isolates (Plate II)

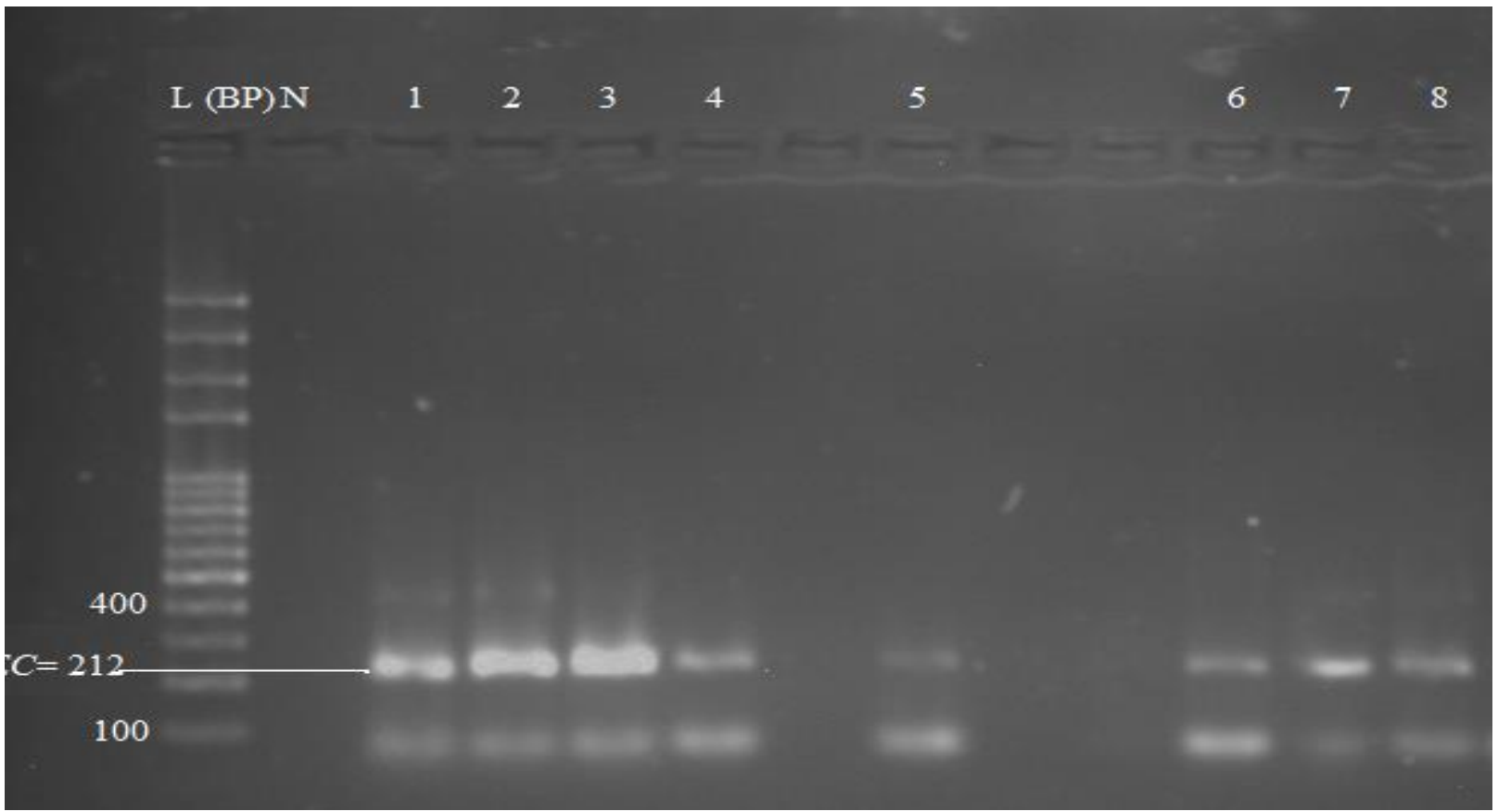

Plate I: well L= DNA ladder (100bp), N= negative control (PCR-mix without DNA), well 1-8= Bands of the EC Genes obtained from the Amplicons of the Samples (EC1-EC8)

Table 1. Antibiotic Sensitivity Profile of the Clinical Isolates of E. coli

\begin{tabular}{|c|c|c|c|}
\hline \multicolumn{4}{|c|}{ Susceptibility Pattern } \\
\hline$($ Content/ $\mu \mathrm{g})$ & No. Sensitive (\%) & No. Interm. (\%) & No. Resistant (\%) \\
\hline SP (10) & $2(25 \%)$ & $0(0 \%)$ & $6(75 \%)$ \\
\hline CPX (30) & $4(50 \%)$ & $0(0 \%)$ & $4(50 \%)$ \\
\hline AM (10) & $0(0 \%)$ & $0(0 \%)$ & $8(100 \%)$ \\
\hline AU (30) & $0(0 \%)$ & $0(0 \%)$ & $8(100 \%)$ \\
\hline CN (10) & $5(62.5 \%)$ & $0(0 \%)$ & $3(37.5 \%)$ \\
\hline PEF (30) & $2(25 \%)$ & $0(0 \%)$ & $6(75 \%)$ \\
\hline OFX (10) & $2(25 \%)$ & $0(0 \%)$ & $6(75 \%)$ \\
\hline $\mathbf{S}(\mathbf{3 0})$ & $3(37.5 \%)$ & $0(0 \%)$ & $5(62.5 \%)$ \\
\hline
\end{tabular}


Table 2: Multiple Antibiotic Resistance (MAR) Index of the Clinical Isolates of $E$. coli $(\mathrm{N}=8)$

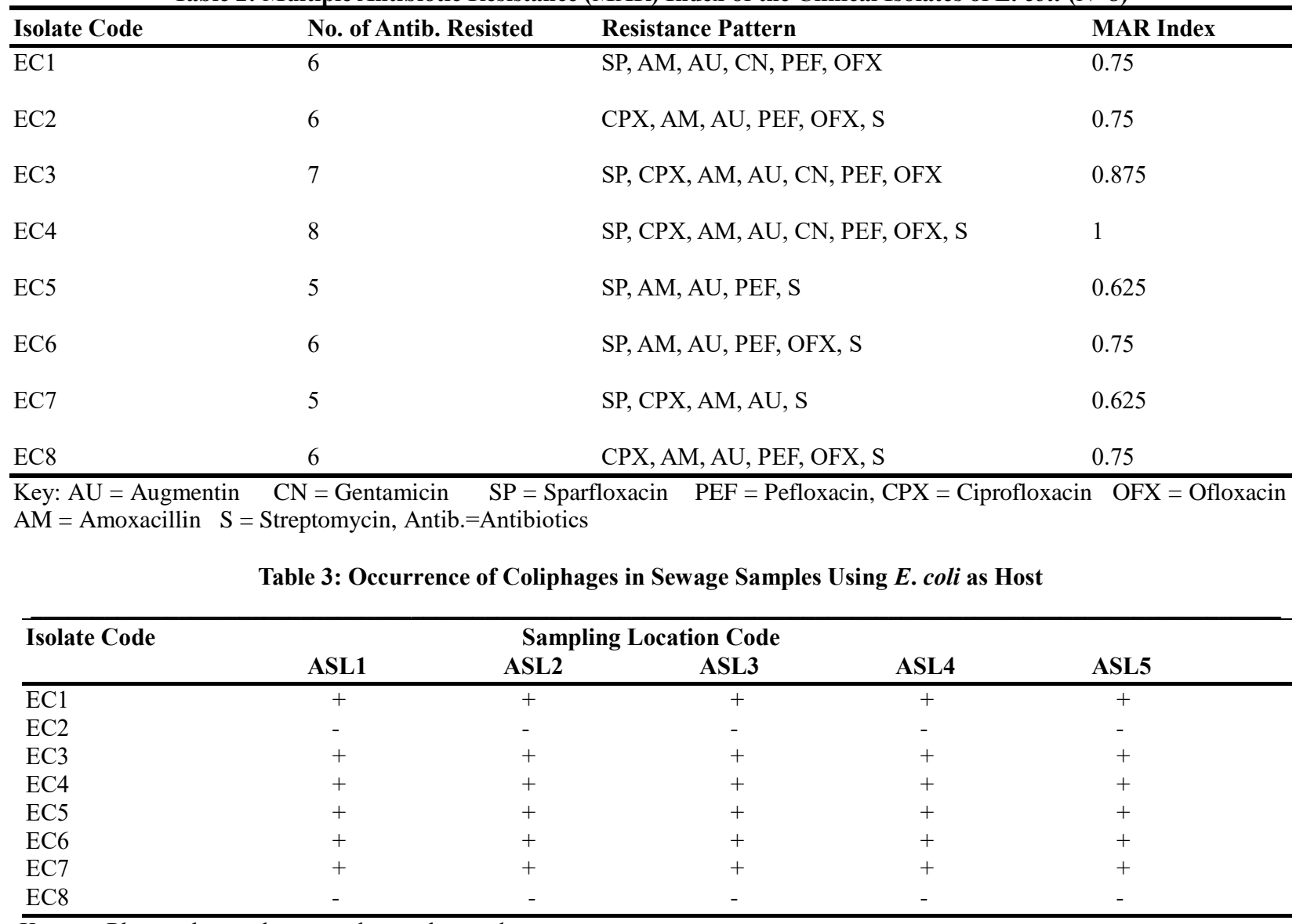

Key:+= Plaque observed, $-=$ no plaque observed

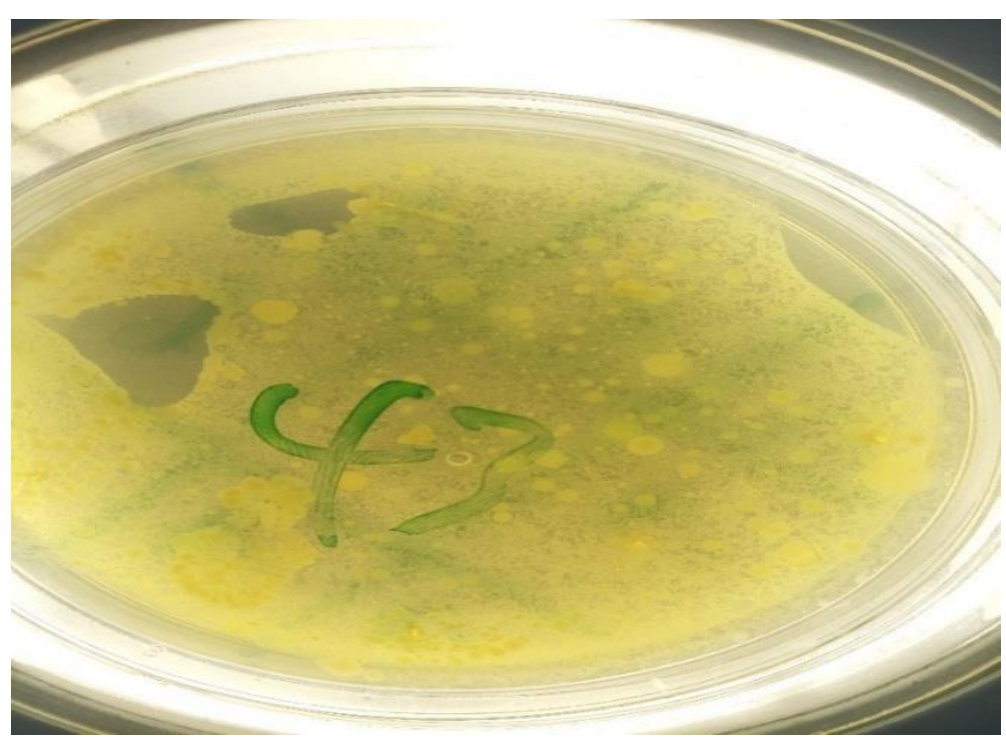

Plate II: Cytopathic Effect of the Various Dilution of Coliphages on MDR E. coli 
Janapriya Journal of Interdisciplinary Studies, 2(1): 96-100.

\section{DISCUSSION}

From our findings, out of the 8 antibiotics tested, only gentamicin and ciprofloxacin showed high level of efficacy, indicating the level of failure of antibiotic therapy! As in conformity, with numerous studies that have recently reported a very high level of bacterial MDR (Alanazi et al., 2018; Yadav and Prakash 2017; Igwe et al., 2016; Dibua et al., 2014; Zhang et al., 2012). Recording much higher significant MAR index in all the isolates used in the study, further suggests that the MDR resistance might have resulted from inappropriate use of antibiotics-an attitude that induce antibiotic resistance but no bacteriophage therapy resistance (Sarker et al, 2016; Sulakvelidze, 2011)

Additionally, from our findings, coliphages are very abundant in nature and the possibility of isolating them from sewage is absolute $(100 \%)$. Furthermore, diluting the coliphage up to $\left(1: 10^{8}\right)$ did not reduce the lytic efficacy of the phage suspension, suggesting the possibility of success of coliphage therapy even when a very low dilution of the coliphage suspension is administered. In conformity with our report, coliphages were previously reported to be abundant in various environments including sewage, regulating the growth of their host bacteria (Sarker et al, 2016).

However, the failure of the coliphage to lysed $2(25 \%)$ of the $E$. coli tested, may suggest that a change in the receptors of the bacteria that recognize that of the coliphage for the successful adsorption of the phage onto the bacterial host, may be one of the determinants of the success of the coliphage therapy, which is in agreement with the work of Shende et al. (2017). It was reported that for the bacteriophage therapy to be successful, receptor recognition must take place between the bacterial host and the specific phage, furthermore, the phage must be able to undergo the lytic pathway, which is associated with the lysis of the bacteria for the release of the progenies (Sulaiman and Usman, 2020). Thus to get the best out of the phage therapy, a cocktail suspension, carrying various classes of the phages has been suggested; for instance absolute (100\%) success was reported in a study where cocktail of the coliphages was administered (Sarker et al, 2016).

\section{CONCLUSION}

The era of successful antibiotic therapy is coming to an end, and inappropriate use of the antibiotics may be one of the factors accelerating it. Coliphages are very abundant in sewage environment and a dilution as low as $1: 10^{8}$ may supply the phages needed for the phage therapy. Implementation of phage therapy can serve as an alternative in the treatment of MDR isolates. A cocktail containing various strains of the phage may improve the success of the therapy.

\section{RECOMMENDATION}

More studies should be carried out to identify the phages that can lyse wider range of bacterial host.

There is a need for the Nigerian government and other stakeholders to invest in this area of research, because the need for alternative to antibiotic therapy may be now!

\section{REFERENCES}

Adhikari, S. (2013). Isolation of Coliphage from Fewa Lake.
Alanazi, M.Q., Alqahtani, F.Y. and Aleanizy F.S. (2018). An Evaluation of $E$. coli in Urinary Tract Infection in Emergency Department at KAMC in Riyadh, Saudi Arabia. Annals of Clinical Microbiology and Antimicrobials, 17(3): 1476-0711.

Balcazar, J.L. (2017). How Do Bacteriophages Promote Antibiotic Resistance in the Environment Clinical Microbiology and Infection, 24:447-449.

Beaudoin, R.N., DeCesaro,R.D., Durkee, D.L. and Susan E. Barbaro, S.E. (2007). Isolation of a Bacteriophage from Sewage Sludge and Characterization of its Bacterial Host Cell. Reviewer Academic Journal, 3(1): 1559-9388.

Cappuccino, J.G. and Sherman, N. (2014). Microbiology: a laboratory manual, 10th edition.www.pearsonhighered.com. Cheesebrough M. (2009). District Laboratory Practice in Tropical Countries. Cambridge University Press, $2^{\text {nd }}$ ed., 9697.

Dibua, U.M., Onyemerela, I.S. and Nueze E.I. (2014). Frequency, Urinalysis and Susceptibility Profile of Pathogens Causng Urinary Tract Infections in Enugu State, Southeast Nigera. Journal of the Institute of Tropical Medicine of Sao Paulo,56(1): 55-59.

Dubey, K., Chandraker, S., Sao, S. and Gupta A., (2015). Isolation and Characterization of Virulent Coliphages from Sewage Sample. International Journal of Current Microbiology and Applied Sciences, 4(12): 2319-7706.

Karthik, K., Muneeswaran, N.S., Manjunathachar, H.V., Gopi, M., Elamurugan, A. and Kalaiyarasu, S. (2014). Bacteriophages: Effective Alternative to Antibiotics. Advances in Animal and Veterinary Sciences,2(35): 1 - 7.

Premarathne, J.M.K.J.K., Thung, T.Y., New, C.Y., Huat, J.T.Y., Basri, D.F., Rukayadi, Y., Nakaguchi, Y., Nishibuchi, M. and Son, R. (2017). Distribution of Bacteriophages in Food and Environment Samples. International Food Research Journal, 24(2): 888-896.

Delmas, J., Dalmasso, G. and Bonnet, R. (2015). Escherichia coli: The Good, the Bad and the Ugly. Clinical Microbiology, 4 (2):195-198.

Igwe, J.C., Olayinka, B.O., Ehnimidu, J.O. and Onaolapo, J.A. (2016). Virulent Characteristics of Multidrug Resistant E. coli from Zaria, Nigeria. Clinical Microbiology 5(6): 268. doi:10.4172/23275073.1000268

Lin, D.M., Koskella, B. and Lin, H.C. (2017). Phage therapy: An alternative to antibiotics in the age of multi-drug resistance. World Journal of Gastrointestinal Pharmacology and Therapeutics, 8(3):162-173.

Lindsey, R.L., Garcia-Toledo, L., Fasulo D., Gladney, L.M. and Strockbine N. (2017). Multiplex polymerase chain reaction for identification of Escherichia coli, Escherichia albertii and Escherichia fergusonii. Journal of Microbiology Methods, 140: 
$1-4$.

Morozova V.V., Vlassov V.V. and Tikunova N.V. (2018) Applications of Bacteriophages in the Treatment of Localized Infections in Humans. Frontiers in Microbiology 9:1696.doi:10.3389/fmicb.2018.01696

Principi, N., Silvestri, E. and Esposito, S. (2019). Advantages and limitations of Bacteriophages for the treatment of bacterial infections. Frontiers in Pharmacology. https://doi.org/10.33091/fphar.201900513

Sarker, S.A., Sultana, S., Reuteler, G., Moine, D., Descombes, P. and Charton, F. (2016). Oral Phage Therapy of Acute Bacterial with Two Coliphage Preparation: A Randomized Trial in Children from Bangladesh. EBio Medicine,4:124-137.

Shende, R.K., Hirpurkar, S.D., Sannat C., Rawat, N. and Pandey, V. (2017). Isolation and Characterization of Bacteriophages with Lytic Activity against Common Bacterial Pathogens. Veterinary World, 10(8): 973-978.

Sulaiman, M.A. and Usman, A. R. (2020). Assessment of Potential Efficacy of Coliphage Therapy on Multidrug Resistant Clinical Isolates of Escherichia coli. UMYU Journal of Microbiology Research,5 (1)49-53.
Sulaiman, M.A., Aminu, M., Ella, E.E. and Abdullahi, I.O. (2020). Characterization of Escherichia albertii, Shigella species and Diarrhoeagenic Escherichia coli from stool samples of gastroenteritis patients in Nano state, Nigeria. Ph.D Thesis, Department of Microbiology, Ahmadu Bello university, Zaria

Sulakvelidze, A. (2011). Bacteriophage. A New Journal for the Most Ubiquitous Organism on Earth,1(1): 1-2.

Wayne, P.A (2018). Performance Standards for Antimicrobial Susceptibility Testing. $28^{\text {th }}$ ed. CLSI supplement M100. Clinical and Laboratory Standards Institute

Yadav, K. and Prakash S. (2017). Screening of ESBL Producing Multidrug Resistant E. coli from Urinary Tract Infection Suspected Cases in Southern Terai of Nepal. Journal of Infectious Diseases Diagnosis, 2(2): 2576-389. 